\title{
Application of Computer in Online Teaching of Professional Courses
}

\author{
https://doi.org/10.3991/ijet.v15i19.17407 \\ Xiaohua Jin \\ Zhongyuan University of Technology, Zhengzhou, China \\ 6561ezut.edu.cn
}

\begin{abstract}
Due to the ongoing public health crisis, computer online teaching has become a new normal. It is very meaningful to explore how to effectively apply computer in online teaching. In this paper, the online teaching situation of teachers and students in a college was surveyed and analyzed. Then, DingTalk, the most popular online teaching platform among the respondents, was introduced in detail. Next, the online teaching situation was tracked, and the learning situation was evaluated in terms of pre-class preparation, in-class teaching, and after-class homework. After that, the satisfaction with the course design and teaching effect was surveyed. The results show that the students felt satisfied with the course design, but regarded practical teaching a weak link in online teaching; the students highly recognized the work attitude, teaching ability, and interactive ability of their teachers, yet calling for better innovation awareness among teachers. The research results provide a good reference for computer-based online teaching of professional courses.
\end{abstract}

Keywords-Computer, online teaching, application, survey.

\section{Introduction}

Under the influence of the public health crisis, it is difficult to conduct face-to-face teaching in colleges. In many countries, the entire curriculum is mainly conducted on the Internet, because the online education itself has been developed for many years and meets their needs of students' education [1-3]. The popularity of the Internet has promoted the development of universal learning. With the support of the digital world, students are placed in a real learning environment through the Internet [4-11].

With the increase of computer network users, the scholars have been more and more interested in computer network as an innovative teaching tool. Osipov et al. [12] introduced an online language learning platform based on computer network which allows voice or video communication between participants, and provides teachers with the prepared teaching materials, bringing great conveniences for teachers and students. Claypool and Claypool [13] added fun factors to the course teaching and developed game-centered teaching software, involving students in practical problems in the game, and improving their participation and positive performance. Bellemare et al. [14] presented a learning environment based on artificial intelligence technology 
platform to achieve the reinforcement learning, model learning, and imitation learning, etc.; the most important is to provide methods for evaluating and solving problems. Simões et al. [15] proposed to apply games to education; for this, a social game framework was built and applied to the social learning environment. Hwang et al. [16] put forward a context-aware learning platform that enables students to provide immediate support as they learn; when learners encounter problems, they can obtain help through the hints given by the learning system; based on the new learning platform, students' learning efficiency and academic performance have been significantly improved. Huang et al. [17] proposed an intelligent learning diagnosis system according to the Web-based theme learning mode, which cannot only train learners' knowledge integration capabilities by selecting topics of interest to learners, help improve their learning behavior, and score teachers' online classrooms, but also predict the learner's achievements, and effectively expand their knowledge.

Hummer et al. [18] believes that online courses attract students to participate, and encourage teachers into the field of online teaching, but as a new teaching method for many teachers, many factors should be taken into consideration before online teaching. Meseguer-Martinez et al. [19] analyzed the number of buttons clicks in the teaching video through the teaching video samples of Spanish national microeconomics and found that users and learners prefer online teaching videos. Dillon and Tucker [20] thinks that online education can change the original education system as an interactive technology, which personalizes learning, meets the needs of each student, ensures quality teaching, and continuously innovates and improves over time. Cavanagh and Mitchelmore [21] studied the computer online teaching process of teachers; through in-depth observation, it's found that teachers did not have any experience when starting to use the online teaching system, and after the guidance, all teachers made some progress in using the system, but not consistently; finally, the implications of online teaching for teacher professional development was discussed, and for those who wish to obtain a final academic degree through distance education, online education is now a viable option. Snelson et al. [22] states that online education can incorporate the use of multiple technologies, including email, social media, blogs, Weibo, Web conferences, learning management systems, forums, and online videos, etc.

Online education increases communication and timely feedback on the course, but it's also faced with some challenges, e.g., online teachers can encounter different technical problems (such as network connection, hardware incompatibility), students lack the experiences in online education, and there is some difficulty in teaching certain procedural topics online [23-25]. Despite of these problem, the new online teaching method has still become an important auxiliary measure of traditional teaching $[26,27]$. Some scholars compare online teaching with face-to-face teaching, tests the effect of both and blended learning, and analyzes the influence of interaction on teaching effect [28-30]. There are different directions for the research of online teaching, such as learning skills and attitudes, the influence of information literacy, and the practice of different courses. Some scholars have carried out research in these aspects [31-34]. Some scholars think that online teaching provides support for learners during the epidemic period, which is more important than before [35-37]. During the epidemic of novel coronavirus pneumonia, educators are trying to teach online and practice, 
and there will be a certain degree of sustainability in the coming period [38, 39]. Due to the importance of online teaching, Kaup et al. [40] Call online teaching a course of the future.

The remainders of this paper are as follows: the second part conducts a survey on the situation of computer online teaching in colleges; the third part introduces DingTalk, the most popular online teaching platform among the respondents; the fourth part is the application of computer in the online teaching; the fifth part summarizes the effect of online teaching; the sixth part is the conclusion of this paper.

\section{Current Situation of Computer Online Teaching}

Facing the public health crisis, Chinese universities generally use computer online teaching. To understand the situation of the computer online teaching, a statistical survey was conducted on the computer online teaching situation of teachers in the School of Energy and Environment of a college. There were 76 respondents, as shown in Figure 1. Among then, 44 respondents used DingTalk online teaching platform, and 16 applied the Tencent Meeting, Tencent Classroom, and QQ) etc., which together accounted for $79 \%$ of the total. Both DingTalk and Tencent platforms operate smoothly, and there is basically no situation when they cannot log in or the webpage cannot be opened. During the large-scale use by teachers and students, they can still maintain the stability of the network, reflecting the advantages of the software platform. Some other platforms have been also adopted before, such as Chaoxing and Yuketang, which were originally used only as an auxiliary measure for face-to-face traditional teaching. There are fewer users on the platform simultaneously, with no network congestion. But due to the large-scale use of network, the users often feel it difficult to log on or open the webpage. Therefore, many teachers give up using software platforms such as Chaoxing and Yuketang and choose a smoother network platform to ensure the quality of teaching. Some teachers still using the software take the form of recorded broadcast and courseware instead of live broadcasting, which enables the course teaching to continue, but the quality of the teaching is not as good as online live broadcasting.

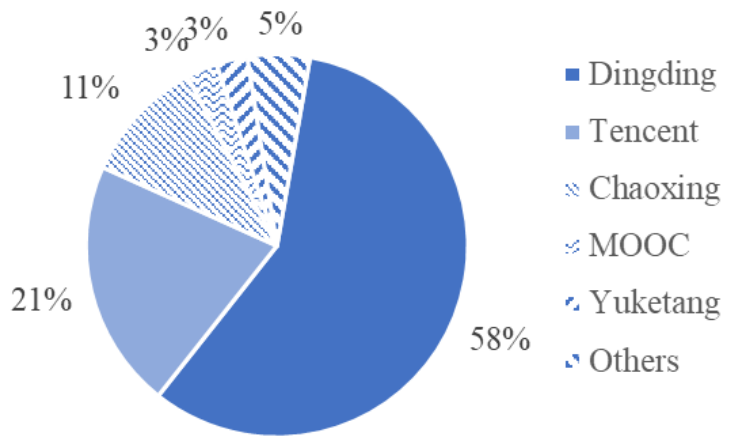

Fig. 1. Use of online teaching platform 
Through the survey, it is found that due to the impact of the public health crisis or the computer network, some teachers and students failed to conduct online teaching and learning. The main reason is that teachers could not return to school in time in high-risk areas and didn't have laptops available. Also, only one teacher of the college has not conducted online computer teaching for personal reasons. The survey was also performed on the reason for some students not attending classes online. The results in Figure 2 show that among these students, those with poor network occupy the largest proportion, 7 in total; some students didn't have computers or other related hardware, or some mountainous areas have no network connections. Most students know the use of online education software, and those who will not use it can master the online education software after learning.

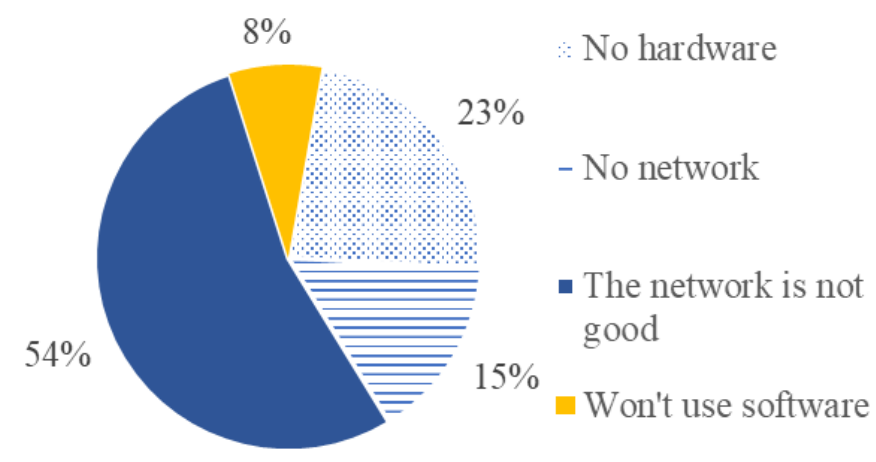

Fig. 2. Reasons for students not attending classes online

\section{Online Software Platform Functions}

The DingTalk software platform is very popular among the online users. To understand the functions of the online software platform, this paper takes the DingTalk software as an example, because its functions are basically similar to other online software platforms. The software working platform is mainly divided into different modules such as safe return to work, school management, teaching assistant, homeschool interconnection, teacher service, student service, and collaborative efficiency, etc. The specific functions related to online teaching mainly include video conference, live broadcast, course sharing, course replay, sign-in function, screen sharing, video playback, communication and interaction, instant testing, homework function, and data export, etc. DingTalk is not only an online teaching platform, but also a school teaching management platform.

The class is created on the platform in the form of the chat group. After all students in the class join the chat, they can be in the class. Figure 3 shows the toolbar of the class group. First, the students in the class group are informed of starting the class on time. Then, by clicking the live button in the DingTalk class group, the teacher can start the live broadcast, enter the theme, and choose the mode, such as camera mode, 
screen sharing mode, or professional mode, etc. After selecting the mode, click to create a live stream. With the option bar at the top of the computer screen, and the interactive panel on the right, click to start the live broadcast. Thus, the class begins. If the students select the save and playback functions of live broadcast, they can watch the playback video after the class. In the class, the teacher can choose to show their chat head or not, and the teacher and the student can interact through the message.

Table 1. Introduction to DingTalk platform functions

\begin{tabular}{|c|c|c|}
\hline Stages & Functions & Description \\
\hline \multirow{4}{*}{ Teaching management } & Sign-in & Learn about students' late and absence \\
\hline & Course replay & Students can watch teaching videos after class \\
\hline & Course sharing & Share the course with students \\
\hline & Home-school group & Establish the home-school connection \\
\hline \multirow{4}{*}{ Teaching process } & screen sharing & $\begin{array}{l}\text { Students can see the teacher's computer interface } \\
\text { through teachers's screen sharing }\end{array}$ \\
\hline & video playback & $\begin{array}{l}\text { Play other videos related to the class on the plat- } \\
\text { form }\end{array}$ \\
\hline & Teacher' chat head & Students can see teachers online \\
\hline & $\begin{array}{l}\text { Communication and inter- } \\
\text { action }\end{array}$ & Realize teacher-student communication function \\
\hline \multirow{3}{*}{ Teaching evaluation } & Instant testing & Take classroom testing of students at any time \\
\hline & Homework function & Assign, collect, and modify homework \\
\hline & Data export & Download the relevant data of the teaching process \\
\hline \multirow{2}{*}{\multicolumn{2}{|c|}{ Expression }} & Videoconferencing \\
\hline & & Send mail \\
\hline
\end{tabular}

Fig. 3. Toolbar of DingTalk class group

\section{Application of Computer in Online Teaching Implementation}

\subsection{Pre-class preparation}

For teachers, pre-class preparation should be made in two aspects: first, in terms of the course, the teachers should prepare the courseware and lesson plans in advance, and get familiar with the teaching content; second, in terms of computer hardware and software, they should prepare the computer, log in to the online software platform, create a class group, add students or let students scan the QR code into the group, send the courseware to the class group in advance, and allow the students to preview.

For students, it is also necessary to prepare hardware such as computers, download and install online teaching software, enter the class group, receive learning materials sent by teachers, preview and preliminarily grasp the content of the course, for better 
understanding the learning content. Afterwards, they are ready for the teachers' live broadcast according to the class schedule.

\subsection{In-class teaching}

In the online teaching, the teacher first initiated the command of sign-in, and the students start to sign in. Within the prescribed time, 26 of the 34 students signed in and 8 did not. In traditional teaching, almost no one is late. In special cases, some students may be late for certain reason. Thus, for computer online teaching, students' self-discipline needs to be improved.

During the teaching process, the teacher-student communication and interaction is carried out through the chat function. If the students do not understand certain problem, they can send a message to the teacher, and the teacher will explain accordingly. The survey on the teacher-student communication and interaction shows that some active students can well communicate with teachers in a timely manner. Due to the convenience of online interaction on the online teaching platform, the overall interaction is better than in traditional teaching. Whereas, there is no much change for students' answering questions, compared with the traditional teaching, i.e., during the online teaching, students are still not active enough in answering questions; when questioned, most students can answer correctly, while a few students answer incorrectly or not.

Throughout the teaching process, the online time of the students was calculated, as shown in Figure 4. It can be seen that 27 of the 34 students could persist until the end of the class; several students had a short class time or left halfway; 1 student was not online. Compared with traditional teaching, computer online teaching is less controlled. It only depends on teachers' regular guidance and students' consciousness. Without the usual teaching supervision mechanism, students become slack in learning discipline.

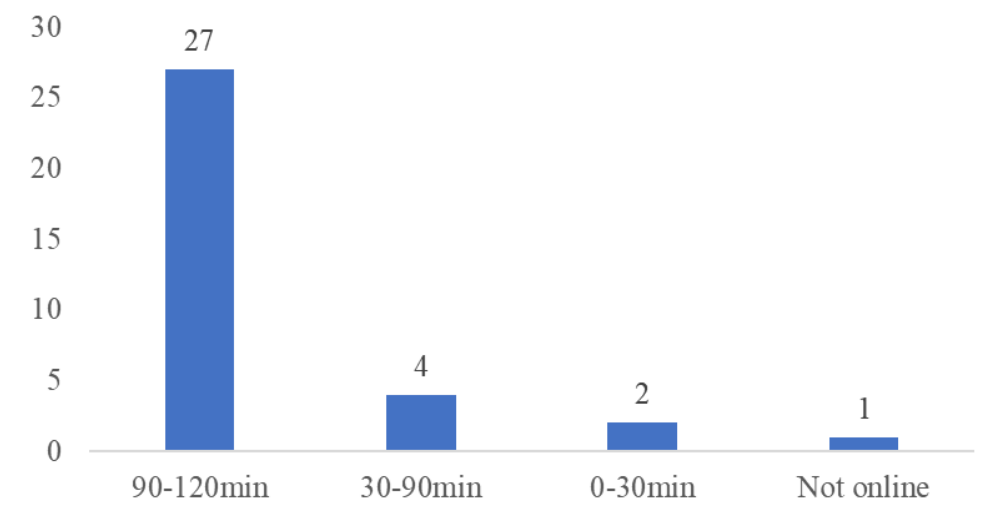

Fig. 4. Students' online time 


\subsection{After-class homework}

Teachers assign homework after class according to the teaching content, and students submit the homework through the online teaching platform. Figure 5 shows the completion of after-class homework. It can be seen that $76 \%$ students completed in time, while a small part of students was delayed. In traditional teaching, such phenomenon of procrastination scarcely occurs, and the homework is uniformly collected. Besides, 2 students have not completed their homework. This is rarely the case in traditional teaching. Thus, online education is inferior to traditional teaching in terms of student supervision and control. The non-face-to-face teaching makes students less awesome.

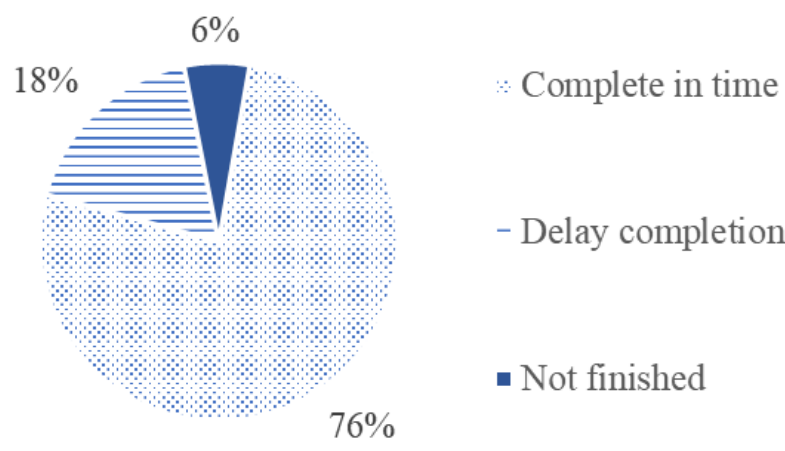

Fig. 5. Completion of students' after-class homework

\subsection{Academic record}

Students' scores are divided into four levels (as shown in Figure 6). 5 students with 90 scores or above, accounting for $14.71 \%$; 13 students with $80-90$ scores, accounting for $38.24 \%$; 13 students with $70-80$, accounting for $38.24 \%$; 3 students with $60-70$, accounting for $8.82 \%$; the average score of students is more than 80 , indicating that the online teaching effect of computer network is good, compared with the traditional face-to-face teaching, students' knowledge of knowledge is better There is little difference in mastery. 


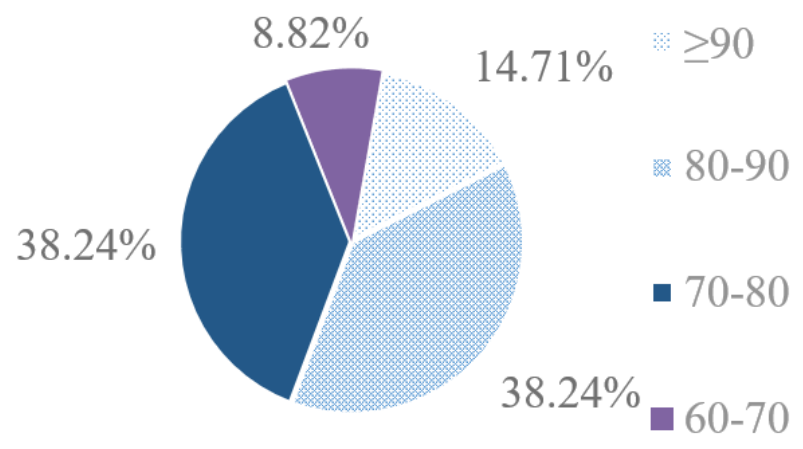

Fig. 6. Academic record

\section{$5 \quad$ Computer Online Teaching Effect}

A survey was conducted on the students' satisfaction with the course design and teacher effect. Satisfaction with course design includes overall satisfaction, training satisfaction and course satisfaction; teaching satisfaction is mainly divided into four aspects: teachers' work attitude, teaching ability, interactive ability, and innovation awareness. 425 valid questionnaires were collected in the survey.

The satisfaction with course design is shown in Table 2. Generally, students felt satisfied with the course design; except for practical teaching, $80 \%$ students were satisfied or very satisfied about the course design, while less than $2 \%$ were dissatisfied and very dissatisfied. Compared with other survey items, practical teaching is less satisfactory, mainly because there is a certain conflict between online teaching and practical teaching, e.g., experiments require students to do it by themselves, but online teaching can only watch the teacher's demonstration video.

Table 2. Students' satisfaction about course design

\begin{tabular}{|l|c|c|c|c|c|}
\hline \multicolumn{1}{|c|}{ Survey items } & Very Satisfied & Ratio & Satisfied & Ratio & General \\
\hline Overall satisfaction & 194 & $45.65 \%$ & 154 & $36.24 \%$ & 72 \\
\hline Training satisfaction & 178 & $41.88 \%$ & 164 & $38.59 \%$ & 77 \\
\hline Liberal education & 190 & $44.71 \%$ & 160 & $37.65 \%$ & 68 \\
\hline Basic course & 190 & $44.71 \%$ & 166 & $39.06 \%$ & 62 \\
\hline Core course & 200 & $47.06 \%$ & 151 & $35.53 \%$ & 69 \\
\hline Practical teaching & 180 & $42.35 \%$ & 155 & $36.47 \%$ & 83 \\
\hline Survey items & Ratio & Dissatisfied & Ratio & Very dissatisfied & Ratio \\
\hline Overall satisfaction & $16.94 \%$ & 4 & $0.94 \%$ & 1 & $0.24 \%$ \\
\hline Training satisfaction & $18.12 \%$ & 5 & $1.18 \%$ & 1 & $0.24 \%$ \\
\hline Liberal education & $16.00 \%$ & 5 & $1.18 \%$ & 2 & $0.47 \%$ \\
\hline Basic course & $14.59 \%$ & 4 & $0.94 \%$ & 3 & $0.71 \%$ \\
\hline Core course & $16.24 \%$ & 3 & $0.71 \%$ & 2 & $0.47 \%$ \\
\hline Practical teaching & $19.53 \%$ & 4 & $0.94 \%$ & 3 & $0.71 \%$ \\
\hline
\end{tabular}


In addition, students' satisfaction about the teaching effect was evaluated by the students, as shown in Table 3. It can be seen that the respondents recognized the teacher's work attitude the highest; $88.94 \%$ were satisfied or very satisfied about the teachers' work attitude, while only $0.95 \%$ were dissatisfied. Satisfaction with teachers' teaching ability and interactive ability is also relatively high, up to more than $86 \%$. Students' satisfaction with teachers' innovation consciousness also accounted for more than $80 \%$, but 9 were dissatisfied or very dissatisfied, accounting for $2.12 \%$, indicating a gap between the survey items. Thus, teachers' innovation consciousness should be improved.

The students evaluated the teaching effect, as shown in Table 4, from four aspects: academic report, learning atmosphere, knowledge mastery and skill mastery. Among them, the learning atmosphere was evaluated the highest, with satisfaction and relatively satisfactory accounting for $83.77 \%$. Secondly, they are satisfied with the academic reports. In all the survey contents, the students' Evaluation on the mastery of skills was poor, with $75.53 \%$ of them were satisfied and satisfied, with the highest proportion of dissatisfaction and very dissatisfaction. Therefore, online teaching has weaknesses in mastering students' skills, especially in classroom experiments and practical exercises, which cannot be operated by hands. Only by recording video and classroom explanation, the expected effect cannot be achieved.

Table 3. Students' satisfaction with the teacher's teaching effect

\begin{tabular}{|l|c|c|c|c|c|}
\hline \multicolumn{1}{|c|}{ Survey items } & Very Satisfied & Ratio & Satisfied & Ratio & General \\
\hline Work attitude & 226 & $53.18 \%$ & 152 & $35.76 \%$ & 43 \\
\hline Teaching ability & 214 & $50.35 \%$ & 163 & $38.35 \%$ & 43 \\
\hline Interactive ability & 213 & $50.12 \%$ & 156 & $36.71 \%$ & 49 \\
\hline Innovation consciousness & 196 & $46.12 \%$ & 159 & $37.41 \%$ & 61 \\
\hline Survey items & Ratio & dissatisfied & Ratio & Very dissatisfied & Ratio \\
\hline Work attitude & $10.12 \%$ & 3 & $0.71 \%$ & 1 & $0.24 \%$ \\
\hline Teaching ability & $10.12 \%$ & 3 & $0.71 \%$ & 2 & $0.47 \%$ \\
\hline Interactive ability & $11.53 \%$ & 6 & $1.41 \%$ & 1 & $0.24 \%$ \\
\hline Innovation consciousness & $14.35 \%$ & 6 & $1.41 \%$ & 3 & $0.71 \%$ \\
\hline
\end{tabular}

Table 4. Satisfaction of teaching effect.

\begin{tabular}{|l|c|c|c|c|c|}
\hline \multicolumn{1}{|c|}{ Survey items } & Very Satisfied & Ratio & Satisfied & Ratio & General \\
\hline Academic report & 200 & $47.06 \%$ & 138 & $32.47 \%$ & 77 \\
\hline Learning atmosphere & 211 & $49.65 \%$ & 145 & $34.12 \%$ & 60 \\
\hline Knowledge mastery & 180 & $42.35 \%$ & 148 & $34.82 \%$ & 87 \\
\hline Skill mastery & 182 & $42.82 \%$ & 139 & $32.71 \%$ & 91 \\
\hline Survey items & Ratio & dissatisfied & Ratio & Very dissatisfied & Ratio \\
\hline Academic report & $18.12 \%$ & 5 & $1.18 \%$ & 5 & $1.18 \%$ \\
\hline Learning atmosphere & $14.12 \%$ & 5 & $1.18 \%$ & 4 & $0.94 \%$ \\
\hline Knowledge mastery & $20.47 \%$ & 7 & $1.65 \%$ & 3 & $0.71 \%$ \\
\hline Skill mastery & $21.41 \%$ & 9 & $2.12 \%$ & 4 & $0.94 \%$ \\
\hline
\end{tabular}




\section{Conclusion}

The statistical survey was conducted on the online teaching situation of teachers and students. It's found that most teachers successfully carried out online teaching and a small number of teachers did not for the hardware or network reasons, while the situation of students is similar to that of teachers, and some students failed to study online due to poor network.

DingTalk and Tencent, as the common online teaching platforms, were taken as examples for statistical analysis, and the related functions were introduced. These functions can ensure the smooth progress of online teaching. Besides, the entire implementation process of class online teaching was also introduced in detail. Compared with traditional teaching, students in the online teaching mode performed better in terms of pre-class preparation, in-class teaching, and after-class homework; the students may become slack in learning discipline due to its weak supervision and control.

The satisfaction with the course design and teaching effect was surveyed. The results show that students had a higher degree of satisfaction about the course design; the respondents were satisfied and very satisfied with course design except for practical teaching, accounting for more than $80 \%$, while practical teaching requires innovative ideas; the students' satisfaction about the teaching effect is generally higher than course design, but teachers' innovation consciousness needs to be improved.

\section{$7 \quad$ References}

[1] TsaI, I. C. (2011). Levels and patterns of participation and social interaction in an online learning community for learning to teach. Journal of Interactive Learning Research, 22(2), 191-239. https://www.learntechlib.org/primary/p/33056/

[2] Andreatta-da-Costa, L. (2016). Using Learning objects to teach structural engineering. International Journal of Online and Biomedical Engineering (iJOE), 12(4), 14-16. https:// doi.org/10.3991/ijoe.v12i04.5014

[3] Hardin, K. (2004). Teach them to fly: Strategies for encouraging active online learning. Online Submission, 5(2), 10-14.

[4] Terblanché, E. (2015). Deciding to teach online: Communication, opportunities and challenges for educators in distance education. Communication, 41(4), 543-563. https://doi.org/10.1080/02500167.2015.1115416

[5] Nuanmeesri, S., Kadmateekarun, P., Poomhiran, L. (2019). Augmented reality to teach human heart anatomy and blood flow. Turkish Online Journal of Educational TechnologyTOJET, 18(1), 15-24.

[6] Shargall, Y., Finley, C., John Agzarian, M. D. (2020). A novel online education module to teach clinicians how to correctly identify ultrasonographic features of mediastinal lymph nodes during endobronchial ultrasound. Canadian Journal of Surgery, 63(1), E62-E68. https://doi.org/10.1503/cjs.000119

[7] Deb, K., Banerjee, S., Chatterjee, R. P., Das, A., Bag, R. (2019). Educational website ranking using fuzzy logic and k-means clustering based hybrid method. Ingénierie des Systèmes d'Information, 24(5), 497-506. https://doi.org/10.18280/isi.240506 
[8] Ashour, A. F. (2020). Design responsibility and sustainability in education. International Journal of Design \& Nature and Ecodynamics, 15(1), 129-133. https://doi.org/10.18280/ijd ne. 150117

[9] Gao L. Q., Liang L., Fen W. N., Gu Y. R., Li Y. H. (2016). Construction of MOOC teaching system for double helix architectural energy saving, Environmental and Earth Sciences Research Journal, 3(2), 31-35. https://doi.org/10.18280/eesrj.030203

[10] Pei, J.Y., Shan, P. (2019). A micro-expression recognition algorithm for students in classroom learning based on convolutional neural network. Traitement du Signal, 36(6), 557-563. https://doi.org/10.18280/ts.360611

[11] Osipov, I. V., Prasikova, A. Y., Volinsky, A. A. (2015). Participant behavior and content of the online foreign languages learning and teaching platform. Computers in Human Behavior, 50, 476-488. https://doi.org/10.1016/j.chb.2015.04.028

[12] Claypool, K., Claypool, M. (2005). Teaching software engineering through game design. ACM SIGCSE Bulletin, 37(3), 123-127. https://doi.org/10.1145/1151954.1067482

[13] Bellemare, M. G., Naddaf, Y., Veness, J., Bowling, M. (2013). The arcade learning environment: An evaluation platform for general agents. Journal of Artificial Intelligence Research, 47, 253-279. https://doi.org/10.1613/jair.3912

[14] Simões, J., Redondo, R. D., Vilas, A. F. (2013). A social gamification framework for a K-6 learning platform. Computers in Human Behavior, 29(2), 345-353. https://doi.org/10.1016/ j.chb.2012.06.007

[15] Hwang, G. J., Wu, C. H., Tseng, J. C., Huang, I. (2011). Development of a ubiquitous learning platform based on a real-time help-seeking mechanism. British Journal of Educational Technology, 42(6), 992-1002. https://doi.org/10.1111/j.1467-8535.2010.0112 $\underline{3 . x}$

[16] Huang, C. J., Liu, M. C., Chu, S. S., Cheng, C. L. (2007). An intelligent learning diagnosis system for Web-based thematic learning platform. Computers \& Education, 48(4), 658679. https://doi.org/10.1016/j.compedu.2005.04.016

[17] Hummer, D., Sims, B., Wooditch, A., Salley, K. S. (2010). Considerations for faculty preparing to develop and teach online criminal justice courses at traditional institutions of higher learning. Journal of Criminal Justice Education, 21(3), 285-310. https://doi.org/10. $\underline{1080 / 10511253.2010 .488108}$

[18] Meseguer-Martinez, A., Ros-Galvez, A., Rosa-Garcia, A. (2017). Satisfaction with online teaching videos: A quantitative approach. Innovations in Education and Teaching International, 54(1), 62-67. https://doi.org/10.1080/14703297.2016.1143859

[19] Dillon, E., Tucker, B. (2011). Lessons for online learning: Charter schools' successes and mistakes have a lot to teach virtual educators. Education Next, 11(2), 50-58.

[20] Cavanagh, M., Mitchelmore, M. (2011). Learning to teach secondary mathematics using an online learning system. Mathematics Education Research Journal, 23(4), 417-435. https ://doi.org/10.1007/s13394-011-0024-1

[21] Snelson, C., Wertz, C. I., Onstott, K., Bader, J. (2017). Using World of Warcraft to teach research methods in online doctoral education: A student-instructor duoethnography. The Qualitative Report, 22(5), 1439-1456.

[22] Rogers, P. C., Liddle, S. W., Chan, P., Doxey, A., Isom, B. (2007). Web 2.0 learning platform: Harnessing collective intelligence. Online Submission, 8(3), 16-33. 
[23] Rasteiro, M. G., Ferreira, L., Teixeira, J., Bernardo, F. P., Carvalho, M. G., Ferreira, A., Ferreira, R.Q., Garcia, F., Baptista, C.M.S.G., Oliveira, N., Quina, M., Santos, L., Saraiva, P.A., Mendes, A., Magalhães, F., Almeida, A.S., Granjo, J., Ascenso, M., Borges, R. (2009). LABVIRTUAL - A virtual platform to teach chemical processes. Education for Chemical Engineers, 4(1), e9-e19. https://doi.org/10.1016/j.ece.2009.02.001

[24] Ramlee, N., Rosli, M.S., Saleh, N.S. (2019). Mathematical HOTS cultivation via online learning environment and 5E inquiry model: Cognitive impact and the learning activities, International Journal of Emerging Technologies in Learning, 14(24), 140-151. https://doi. org/10.3991/ijet.v14i24.12071

[25] Songsom, N., Nilsook, P., Wannapiroon, P., Fung, C. C., Wong, K. W. (2019). System architecture of a student relationship management system using Internet of Things to collect digital footprint of higher education institutions, International Journal of Emerging Technologies in Learning, 14(23), 125-140. https://doi.org/10.3991/ijet.v14i23.11066

[26] Wright, J. M. (2014). Planning to meet the expanding volume of online learners: An examination of faculty motivation to teach online. Educational Planning, 21(4), 35-49.

[27] Szeto, E. (2014). A comparison of online/face-to-face students' and instructor's experiences: Examining blended synchronous learning effects. Procedia-Social and Behavioral Sciences, 116(21), 4350-4254. https://doi.org/10.1016/j.sbspro.2014.01.926

[28] Kalpokaite, N., Radivojevic, I. (2020). Teaching qualitative data analysis software online: A comparison of face-to-face and e-learning ATLAS. ti courses. International Journal of Research \& Method in Education, 43(3), 296-310. https://doi.org/10.1080/1743727x.2019. $\underline{1687666}$

[29] Wang, Y., Liu, Q. (2020). Effects of online teaching presence on students' interactions and collaborative knowledge construction. Journal of Computer Assisted Learning, 36(3), 370382. https://publons.com/publon/10.1111/jcal.12408. https://doi.org/10.1111/jcal.12408

[30] Terrell, S. R. (2014). Introduction to the special section of the internet in higher education: The American educational research association's online teaching and learning special interest group. The Internet and Higher Education, (21), 16-33. https://doi.org/10.1016/j.ih educ. 2014.01.001

[31] Goodsett, M. (2020). Best practices for teaching and assessing critical thinking in information literacy online learning objects. The Journal of Academic Librarianship, 102163. https://doi.org/10.1016/j.acalib.2020.102163

[32] Feng, Q.Q. (2020). Research on teaching practice of "introduction to linguistics" open online courses. International Journal of Social Science and Education Research, 3(6), 8698.

[33] Bravo, E.D. (2020). Audit analysis of online learning skills and attitudes of students in Carig campus of Cagayan state university: The basis of teaching and learning innovation. Journal of Research in Vocational Education, 2(5), 31-45.

[34] Gacs, A., Goertler, S., Spasova, S. (2020). Planned online language education versus crisis prompted online language teaching: Lessons for the future. Foreign Language Annals, 53(2): 261-273. https://doi.org/10.1111/flan.12460

[35] Yen, T. F. T. (2020). The Performance of Online Teaching for Flipped Classroom Based on COVID-19 Aspect. Asian Journal of Education and Social Studies, 57-64. 
[36] He, T., Ma, A.M. (2020). Practice and discussion on online teaching of university pe during the period for prevention and control of COVID-19. International Journal of Education and Economics, 3(2), 68-81.

[37] Parisi, M. C. R., Frutuoso, L., Benevides, S. S. N., Barreira, N. H. M., Silva, J. L. G., Pereira, M. C., Cecilio-Fernandes, D. (2020). The challenges and benefits of online teaching about diabetes during the COVID-19 pandemic. Diabetes \& Metabolic Syndrome, 14(4), 217-232. https://doi.org/10.1016/j.dsx.2020.04.043

[38] Bao, W. (2020). COVID 19 and online teaching in higher education: A case study of Peking University. Human Behavior and Emerging Technologies, 2(2), 113-115. https:// doi.org/10.1002/hbe2.191

[39] Kaup, S., Jain, R., Shivalli, S., Pandey, S., Kaup, S. (2020). Sustaining academics during COVID-19 pandemic: The role of online teaching-learning. Indian Journal of Ophthalmology, 68(6), 1220-1221. https://doi.org/10.4103/ijo.ijo_1241_20

\section{Author}

Xiaohua Jin is from Linzhou City. He has done Ph.D. and is a master supervisor. His research interests include safety management, behavior safety, safety culture, etc.

Article submitted 2020-06-30. Resubmitted 2020-08-03. Final acceptance 2020-08-05. Final version published as submitted by the authors. 